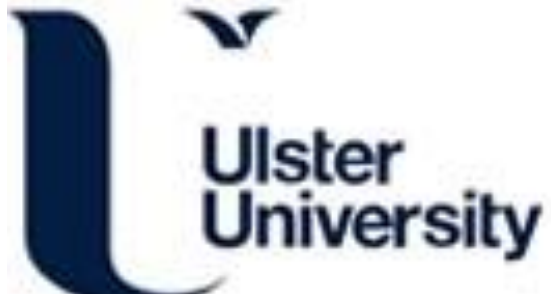

\section{A systematic review of electronic assistive technology within supporting living environments for people with dementia}

Daly-Lynn, J., Rondon-Sulbaran, J., Quinn, E., Ryan, AA., mcCormack, B., \& Martin, S. (2019). A systematic review of electronic assistive technology within supporting living environments for people with dementia. Dementia, 18(7-8), 2371-2435. https://doi.org/10.1177/1471301217733649

Link to publication record in Ulster University Research Portal

Published in:

Dementia

Publication Status:

Published (in print/issue): 01/11/2019

DOI:

$10.1177 / 1471301217733649$

\section{Document Version}

Author Accepted version

\section{General rights}

Copyright for the publications made accessible via Ulster University's Research Portal is retained by the author(s) and / or other copyright owners and it is a condition of accessing these publications that users recognise and abide by the legal requirements associated with these rights.

\section{Take down policy}

The Research Portal is Ulster University's institutional repository that provides access to Ulster's research outputs. Every effort has been made to ensure that content in the Research Portal does not infringe any person's rights, or applicable UK laws. If you discover content in the Research Portal that you believe breaches copyright or violates any law, please contact pure-support@ulster.ac.uk. 
A systematic review of electronic assistive technology within supporting living environments for people with dementia

Jean Daly Lynn ${ }^{1}$, Janeet Rondón-Sulbarán ${ }^{2}$, Eamon Quinn ${ }^{1}$, Assumpta Ryan ${ }^{3}$, Brendan McCormack $^{4}$ and Suzanne Martin ${ }^{2}$

${ }^{1}$ Engage With Age, Belfast, Northern Ireland

${ }^{2}$ School of Health Sciences, Ulster University, Newtownabbey, Northern Ireland

${ }^{3}$ School of Nursing, Ulster University, Magee, Northern Ireland

${ }^{4}$ Head of Division of Nursing, Queen Margaret University, Scotland

\section{Corresponding author:}

Jean Daly Lynn

Engage With Age, 55 Templemore Avenue, Belfast, Northern Ireland

Email: jean.daly@engagewithage.org.uk

\section{Abstract}

Health and social care provision needs to change in order to meet the needs of an increase in the number of people living with dementia. Environmental design, technology and assistive devices have the potential to complement care, help address some of the challenges presented by this growing need and impact on the lived experience of this vulnerable population. This systematic review was undertaken to identify the research on the use of electronic assistive technology within long-term residential care settings. A total of 3229 papers published from the inception of each of the databases up until May 2016 were retrieved from searches in four major databases. Sixty-one were identified to be included in the review. The inclusion criteria were: original peer reviewed journals; an electronic assistive technology intervention; with residents or tenants living with dementia or their family or paid caregivers; in supported living environments or residential care. The data extracted from the included studies focused on the methodology, technology, outcomes and the role of people 
living with dementia within the research. Overall, an extensive variety of technical interventions were found, with a broad range of methodological heterogeneity to explore their effect. Additionally, wide-spanning outcomes to support of the potential of technology solutions and the challenges presented by such intervention were found.

\section{Keywords}

Dementia, telecare, assistive technology, systematic review, long-term care Introduction

Dementia is an umbrella term for a cluster of symptoms that damage and destroy brain cells having a profound effect on a person's cognitive ability. This degenerative condition greatly interferes with the normal aging process and can significantly impact on independence and quality of life. Each presentation of dementia is unique depending on the severity, progress of condition, type of dementia, and the subjective experience of the symptomology. Currently, there is no cure for this chronic condition so long-term dependence on care provision is often inevitable. Cognitive impairment is the most common feature of these diseases affecting communication, language, understanding, mood, and impacting on everyday tasks. Neuropsychiatric symptoms such as depression, stress, irritability, agitation, anxiety, disinhibition can also manifest in a number of ways (Lyketsos et al., 2012).

The demographic change means that across the world, people are living longer and a corollary of this phenomenon is that dementia prevalence rates are on the rise . Over 46.8 million people worldwide are reported to be living with dementia (Alzheimer's Disease International, 2015). The current challenge for governments is to develop health and social care services to 
cope with this growing need and in doing so support the quality of care for people living with dementia, their caregivers and their families. Research in developed countries has indicated that dementia is associated with huge economic implications and this is expected to continue to rise (Wimo et al, 2013). Thus, within high-income countries dementia care has become a governmental priority (Prince et al, 2013). Electronic health solutions have been described as essential tools to providing cost-effective, quality health care services to aging populations (Martínez-Alcalá, Pliego-Pastrana, Rosales-Lagarde, Lopez-Noguerola, \& Molina-Trinidad, 2016). Technology and assistive devices have the potential to enhance the long-term care needs of people living with dementia and their caregivers. Additionally, technology can enhance knowledge exchange, education, and virtual environments, in turn, increasing the standards of the care environments (Martínez-Alcalá et al., 2016).

Technology is considered useful in the lives of people living with dementia to promote independence, improve quality of life, manage risk and increase safety, support all users (people with dementia, family, caregivers) and to personalise support (Cahill, Begley, Faulkner, \& Hagen, 2007). The word 'technology' is in itself a very broad term, spanning a wide range of devices with different functionalities. It is a term that describes assistive devices that can support people living with dementia with prompts and reminders, alarm systems, automatic lights, domestic appliances that switch themselves off at a certain point, easy to use remote controls and phones, monitoring, and therapeutic interventions (Buckley, 2006). Pervasive telecare technologies include a range of sensors to detect motion, pressure, inactivity, falls and temperature which automatically send a signal to a carer or monitoring centre to provide assistance when it is needed. Surveillance technologies that enable constant monitoring of the user include wearable devices such as electronic tracking chips, 
and Global Positioning Systems (GPS) locators that can locate a person if they get lost, and alarm pendants and bracelets can call for assistance in the event of an emergency. This is also know as localization technology (Øderud, Landmark, Eriksen, \& Berit, 2013). Traditionally, when people with dementia are living at home they may use the alarm to remotely monitor their home or, for example, stand-alone devices to support memory or medication management. Within more cluster supported living, for instance, residential accommodation networked information systems based on sensor technologies may be used. Assistive technologies such as touchscreen devices can be used for entertainment and quality of life to support reminiscence through pictures, music and Apps, and as memory aids. Although technology provision of people living with dementia tends to focus more on safety and the reduction of risk, as opposed to devices for leisure and promoting well-being. Innovative devices are continually emerging into the marketplace and as research prototypes which means technology to support people living with dementia is a very fluid environment.

Within the United Kingdom (UK), it is estimated there are 1.7 million telecare users, 171 technology products and 331 services for people living with dementia (Gibson et al., 2014). Despite this, assistive technology provision is fragmented, it can be difficult to access, and devices to support well-being and quality of life often fall outside the scope of provision (Gibson et al., 2014). A number of literature reviews have already been undertaken to explore the impact of assistive technology within the lives of people living with dementia. One review stated that more robust evidence is needed to explore the impact assistive technology can have in the care of people living with dementia (Fleming \& Sum, 2014). Forty-one papers met the inclusion criteria in the review, and in their findings reported that the evidence for the effective use of assistive technology to improve the safety and security of people with 
dementia is very weak. Common issues reported were difficulties using systems, lack of acceptance by the user and the reliability of the technology. Recommendations within the review included the need for careful assessment, early introduction of technology, personalised technology approaches and more robust evidence. Topo (2009), reported in her literature review, that the majority of the sixty-six studies included were undertaken in residential care or hospital settings primarily concerned with the needs of formal caregivers. The findings indicated that more robust research is needed, the cost effectiveness is currently unknown and personalisation of technology for users is important. The challenges in this field are because there is such a wide variability of aims, the technology design and outcome measures. Additionally, it was reported that the voice of people living with dementia is limited within academic literature. Another significant literature review had a specific focus on surveillance technologies both for people living with dementia and intellectual disability within a residential care setting (Niemeijer et al., 2010). A total of seventy-nine papers met the inclusion criteria from international sources. A wide range of themes emerged from the findings, including functional efficacy, duty of care versus autonomy, freedom and consent, safety/risks, substitution of care, dignity/stigmas, staff burden, person-centred care, and privacy. A major conflict emerged between the interests of the institution and the interest of the resident, especially in relation to technologies impact on the resident's quality of life. Additionally, a lack of in-depth analysis was evident and no agreement on the ethical application of technology was reached. Importantly, the residents' perspectives were not often included and therefore lacking the first person account of the experience of technology.

The use of technology within care at present and in the future has not been formulated into a clear plan (Sugihara, Fujinami, Phaal, \& Ikawa, 2013). Little evidence indicates the changing 
technology requirements as a person's dementia progresses. Additionally, some technologies would not be as suitable for those at a more advanced stage of dementia or for those living within a residential or nursing home (Olsson, Engström, Skovdahl, \& Lampic, 2012). A key role in the provision of technology enriched care is enabling a person with dementia to live in their own home environment for longer (Leroi et al., 2013; Zwijsen, Niemeijer, \& Hertogh, 2011). However, as housing options increase so too should the provision of technology enabled services to enhance care and increase quality of life. The current literature review will focus our attention on long-term care and supported living environments. The previous literature reviews have been vital in the preparation for the current review (Fleming \& Sum, 2014; Niemeijer et al., 2010; Topo, 2009). Although two of these reviews targeted the more generic provision of technology (Fleming \& Sum, 2014; Topo, 2009) and one was specifically on surveillance technology (Niemeijer et al., 2010), the three works constituted an important knowledgebase for technology available for people living with dementia. This systematic review will attempt to further expand this knowledge base by providing an overview of the technologies in use within residential care settings and the methodologies employed to assess the impact of such interventions. In addition to this, we will determine the extent to which people living with dementia have an active participant role in these studies as previously, they were not considered to contribute in research due to their cognitive impairment (Higgins, 2013). Therefore, it would be important to explore the extent to which this has changed and the approaches used for successful engagement.

Research Questions

Primary Aim 
- What technologies do people living with dementia use in supportive living environments and residential care?

Secondary Aim

- Are people with dementia included in studies exploring these technologies?

\section{Methods}

\section{Search Strategy}

We performed a systematic search of the following databases: Embase (1974-2016), Medline (1993-2016), PsychInfo (1872-2016) and CINAHL (1937-2016). Additionally, reference lists of identified journals were screened. We included all studies published up until May 2016. The search terms derived from previous reviews of the literature ${ }^{1}$ and support from the University librarian.

The following search terms were used:

(Dement\$ OR Alzheimer\$ OR cognitive adj3 impairment\$)

AND

(nursing adj3 home\$ OR assisted adj3 living OR residential adj3 care OR support\$ adj3 living OR care adj3 home\$)

AND

${ }^{1}$ (Topo, 2009; Fleming \& Sum, 2014; Labonnote \& Høyland, 2015) 
(tech\$ OR assistive adj3 device\$ OR smart adj3 home\$ OR telecare OR alarm adj3 system\$

OR intercom\$ OR sensor\$ OR actuator\$ OR alarm adj3 bracelet\$ OR bed adj3 alarm\$ OR motion sensitive light\$ OR fall adj3 detector\$ OR activit\$ adj3 monitor\$ OR tracking adj3 device\$ OR monitor\$ OR wearable adj3 device\$ OR surveillance)

\section{Inclusion criteria}

We included studies that met the following criteria: original peer reviewed papers; an assistive technology intervention; with residents or tenants living with dementia or their caregivers; in supported living environments or residential care. Technology devices included were: motion sensors, inactivity sensors, acoustic sensors, bed sensors, surveillance technology, electronic bracelets and pendants, intercom or speakers, automatic lighting, alarms, automatic doors, GPS tags, fall detectors, cameras, caregiver platforms or handheld devices, and electronic devices to support actives of daily living.

\section{Exclusion criteria}

Studies were excluded if they were not in the English language, or if presented as reports, commentaries, conference abstracts and review articles. We also excluded technology interventions used within the persons own home and hospital based interventions in addition to studies where the level of technological intervention was not clear (e.g. Snoezlen).

\section{Selection of Studies}

All retrieved titles were inputted into the reference manager RefWorks and the duplicates were removed. During the initial screening process, the title, keywords and abstracts were reviewed by one researcher to identify the relevant papers. Of the 2311 retrieved citations 
131 were identified for closer examination. The 131 papers were reviewed against the inclusion criteria and a further 89 were excluded. A number of papers were brought to the research team to consider and inclusion was decided in consultation with the team. The number of full papers included was 42 and the data was extracted. The included papers were divided according to the technical intervention: Telecare, Light therapy, Robotics, Well-being and leisure, Simulated presence, and Orientation and activities of daily living. Each theme that emerged was independently hand searched within the Cochrane Library and inputted into Google Scholar to pick up any systematic reviews or missing papers on that topic. The reference lists of the included studies and relevant literature reviews were also inspected. Another 19 papers were added from the hand searches of the literature. The final number of included papers was $\mathrm{N}=61$ (Figure 1). A Cochrane Review on light therapy was identified (Forbes et al., 2014) which led to the inclusion of two out of the four light therapy studies reviewed in the present work.

Figure 1. The Search Strategy Flowchart

Data Synthesis

The PRISMA checklist for systematic reviews was adopted to inform the data extraction (Moher, Liberati, Tetzlaff, Altman, \& Grp, 2009). The main focus during the data extraction was to explore the following characteristics in each of the included studies: the purpose of the study; the participants; the setting; the methodological design; data analysis; technology intervention; ethical considerations; the voice of person with dementia; and the outcome of 
the study. Two members of the research team undertook the data extraction (JDL and JRS). The data was appraised descriptively in terms of each technical intervention.

\section{Results}

A total of 61 studies were included in this review. We extracted data directly from 59 studies as two of the reviewed studies were included in a Cochrane Review in which the data was extracted from (See Table 4) (Ancoli-Isreal et al., 2003; Thorpe, Middleton, Russell, \& Stewart, 2000). The papers retrieved were published between 1995 and 2016. A wide range of methodological approaches within the studies were adopted and illustrated in Table 1.

*=unspecified measures used

Table 1. Methodological approaches used within included studies

Telecare

Twenty-three of the studies reviewed focused on a telecare technology intervention in a long term-care setting (Table 2). There was a wide range of methodological heterogeneity with twenty different screening tools and outcome measures. The methodological approaches are set out in Table 1. The overall aims of these studies included usability testing of monitoring systems, accessing the impact of technology to support night-time needs, testing specific telecare devices and gathering perceptions of telecare interventions. A number of studies 
reported positive outcomes for the use of telecare systems and devices (Aloulou et al., 2013; Bourennane, Charlon, Bettahar, Campo, \& Esteve, 2013; Miskelly, 2004). The findings highlight the potential to improve safety and reduce the need to invade a person's privacy through the adoption of a monitoring system (Yayama et al., 2013). Other outcomes included residents having a sense of security (Margot-Cattin \& Nygård, 2006), technology obtaining information that staff observation might not (Yamakawa, Suto, Shigenobu, Kunimoto, \& Makimoto, 2012), and the promotion of independence (Martin et al., 2013). Interestingly, one paper reported that surveillance technology was used with residents living with a less advanced stage of dementia and as the condition progressed physical restraint interventions were more likely to be used (Te Boekhorst et al., 2013). Niemeijer and his team reported surveillance technologies in care to be both enabling and an invasion of privacy (Niemeijer, Depla, Frederiks, \& Hertogh, 2015).

\section{Table 2. Characteristics of Telecare Intervention Studies}

A number of technical issues that emerged with telecare included the number of false alarms (Capezuti, Brush, Lane, Rabinowitz, \& Secic, 2009), the reliability of devices (Godwin, 2012), low batteries, connection problems (Aloulou et al., 2013), and alarm fatigue (Niemeijer, Depla, Frederiks, Francke, \& Hertogh, 2014). Alarm fatigue occurs when the technology produces recurring false positives alerting caregivers unnecessarily when residents do not need support. This can lead to frustration among staff, and in some cases can result in turning the alarm off (Niemeijer et al., 2014). Additionally, telecare doesn't ensure quick assistance (Zwijsen, Depla, Niemeijer, Francke, \& Hertogh, 2012) and no significant relationship between the reduction of falls and technology interventions were found (Bressler, Redfern, \& Brown, 
2011; Holmes et al., 2007). One study found that staff had a fear and reluctance around the integration of technology into care, with particular concerns around the impact on the care relationship and the reliability of technology (Niemeijer et al., 2014). Another study reported that people with dementia do not like to be monitored (Godwin, 2012). Maintaining the persons with dementias privacy and restricting individual's liberty are important emerging issues that also need further percolation in order to enhance care and autonomy. Additionally, the cost of technology interventions were also noted as a potential shortcoming (Altus, Mathews, Xaverius, Engelman, \& Nolan, 2000). Recommendations included the need for systems to be personalised and individual (Aloulou et al., 2013; Niemeijer et al., 2015), and individual person-centred assessment for devices are required (Godwin, 2012). The design of telecare solutions should also be improved in the future according to the user's needs with people living with dementia part of the design process (Abbate, Avvenuti, \& Light, 2014) and the potential for failure at the core to help remedy solutions (Aloulou et al., 2013). Further systematic and robust research is needed to increase usability and enable the practical application of such interventions (Bourennane et al., 2013; Godwin, 2012; Martin et al., 2013; Schikhof, Mulder, \& Choenni, 2010). Consideration also needs to be given to obtaining consent for the use of telecare with tenants and residents (Miskelly, 2004). The range of telecare technologies reported in the $\mathrm{N}=23$ studies were vast and are illustrated in Table 3.

Table 3. Devices and Systems reported with Telecare Intervention Studies 
Light therapy

The initial search retrieved three papers focused on light therapy (Aarts, Aries, Straathof, \& Hoof, 2014; Ancoli-Isreal et al., 2003; Thorpe et al., 2000) Further searches found that a Cochrane Review was undertaken in 2014 (Forbes et al., 2014). Studies that cited the Cochrane Review were subsequently searched and one met the inclusion criteria (van Wezel, Zwerts-Verhelst, Sturm, \& van Hoof, 2016). The data was not extracted from two studies as they were assessed within the Cochrane Review (Ancoli-Isreal et al., 2003; Thorpe et al., 2000). Therefore, the data was extracted from the Cochrane Review and two further studies subsequently published (Table 4).

\section{Table 4. Characteristics of Light Therapy Intervention Studies}

The two retrieved studies explored the opinions of professional caregivers of dynamic lighting systems (Aarts et al., 2014; van Wezel et al., 2016). In one study, the DLS were purchased to improve residents well-being and their sleep/wake rhythm (Aarts et al., 2014). Care staff saw no effect from the DLS, however, no data were collected to evaluate the effectiveness of DLS. Interestingly, care professionals reported being happy to use DLS if it improved the well-being of residents and they had a belief that DLS can provide positive outcomes (van Wezel et al., 2016). The findings of the Cochrane review do not recommend bright light therapy in practice due to the lack of evidence. Only one study out of 11 randomised control trials indicated a positive effect. The review raised a number of questions such as: what time of the day is best to use a light therapy intervention? What is the recommended illumination intensity? What is the optimum length of exposure time? Which type of light therapy approach is best? More 
robust research is needed to determine if light therapy can in fact have a positive effect and could be recommended to use in practice. A second review using the same studies explored the literature from an engineering perspective (Aarts et al., 2016). The heterogeneity in the light interventions were reported and the studies were described as low quality. It was stated that exposure to day light is a methodological flaw that is frequently not recorded. Recommendations included the need for multidisciplinary studies and guidance on effective light doses for participants.

Robotic companions

A total of $\mathrm{N}=12$ studies were retrieved focused on robotic companion interventions (See Table 5). A further three literature reviews were identified on the use of social robotic companions (Broekens, Heerink, \& Rosendal, 2009; Kachouie, Sedighadeli, Khosla, \& Chu, 2014; Mordoch, Osterreicher, Guse, Roger, \& Thompson, 2013). The original search terms did not specify robotics and this theme emerged naturally from the literature relating to assistive technology and individuals living with dementia. Therefore, this section only aims to provide an overview of the current status of robotic companion interventions in residential environments.

\section{Table 5. Characteristics of Robotic Companion Intervention Studies}

A total of five different types of robot companions were evaluated within the included studies. Eight studies focused on PARO, a robot that looks like a baby seal with a range of sensors that enable PARO to respond to voice and touch stimuli. In one study, a robotic cat called $\mathrm{NeCoRo}^{\circledR}$ covered with synthetic fur is able to interact with the user by making a meow noise and tail wagging was compared 
to a plush cat (Libin \& Cohen-Mansfield, 2004). Another study compared a toy dog to the AlBO robotic dog that responds to a wide range of spoken commands (Tamura, Yonemitsu, Itoh, Oikawa, \& al, 2004). Additionally, a touchscreen robot called Guide that displays messages, is interactive, takes and stores vital sings, has entertainment applications, Skype and brain fitness games (Robinson et al., 2013) and a prototype robotic teddy bear called CuDDler with three degrees of freedom to move which responds to the user appropriately either by external control through a software module. The findings highlighted the potential for socially assistive robotics to reduce agitation (Libin \& CohenMansfield, 2004), depression (Jøranson, Pedersen, Rokstad, \& Ihlebæk, 2015), increase interaction between residents (Pfadenhauer \& Dukat, 2015; Šabanovic, Bennett, Chang, \& Huber, 2009; Tamura et al., 2004) and have a therapeutic impact (Bemelmans, Gelderblom, Jonker, \& de Witte, 2015). One study found both the toy dog and AIBO increased interactions during an occupational therapy session with people living with severe dementia however participants identified more with the toy dog (Tamura et al., 2004). Additionally, not all participants accepted the robotic companion (Moyle et al., 2016). Families were reported to find the use of PARO challenging (Bemelmans, Gelderblom, Jonker, \& de Witte, 2016) and it was highlighted that PARO should complement not replace care workers (Pfadenhauer \& Dukat, 2015). This kind of research is in its infancy and more research is needed to determine usability features in order to create an adult appropriate design (Moyle et al., 2016) with a particular focus on user centered design (Robinson et al., 2013).

Well-being and leisure 
Studies focusing on technology solutions to support the well-being and leisure of people living with dementia in long-term care setting are illustrated in Table 6. Eight studies were identified. The purpose of this research ranged from increasing physical activity through technology interventions, developing a cognitive rehabilitation system, a touchscreen device to increase well-being and the usability of a watch that measures sleep/wake patterns and circadian rhythms. Technology interventions were found to increase physical activity without a rise in staff workload (Braun et al., 2014), improve cognition (Burdea et al., 2014), complement person-centred care (Kerssens, Sattler, \& Monteiro, 2014), increase communication and socialisation (Nijhof, van Hoof, van Rijn, \& van Gemert-Pijnen, 2013) and were enjoyable (Torrington, 2009). Additionally, it was found that a monitoring watch was a time saver for staff and reduced any disturbance to residents during the night, however, changes to the system features were required and significant effort was reported by staff in order to implement the intervention (Nijhof, van Gemert-Pijnen, de Jong, Ankoné, \& Seydel, 2012). Similarly, health and well-being changes could be identified through changes reported in the technical data, however, it can be difficult to determine what this change means for the persons health (Paavilainen, Korhonen, \& Partinen, 2005). Further research is recommended with larger sample sizes and incorporating a randomised control trial approach (Burdea et al., 2014; Padala et al., 2012).

Table 6. Characteristics of Well-being and Leisure Intervention Studies 
Simulated presence therapy refers to personalised audio or video recordings made by a caregiver or family member and played to a person living with dementia to bring comfort and reduce any challenging behaviours (Zetteler, 2008). Three studies were retrieved from the original search and a further six were obtained through further searches. A systematic review and meta-analysis was published by Zetteler, (2008). Additionally, a Cochrane review protocol was published by Abraha et al., (2015) therefore, a comprehensive review of simulated presense for people living with dementia is imminent in the near future. Primarily, the nine studies included within this review focused on the evaluation of simulated presence therapy and its ability to reduce negative behaviours (Table 7). One study explored the use of personal message cards as an alternative to creating the more extensive audio files (Evans, Cheston, \& Harris, 2015).

\section{Table 7. Characteristics of Simulated Presence Intervention Studies}

Generally, the outcome from the simulated presence therapy was successful at enhancing well-being and reducing disruptive behaviours (Camberg, Woods, Ooi, \& Hurley, 1999; CohenMansfield \& Werner, 1997). One study reported that simulated presence and music were both more effective that usual care (Garland et al., 2007). However, a second study did not find music to be a preferred intervention (Cheston, Thorne, Whitby, \& Peak, 2007). Interestingly, families requested to continue the use of simulated presence after one study had ended (Woods \& Ashley, 1995). Finally, it was reported that when the intervention was withdrawn the effects were reversed (O'Connor, Smith, Nott, Lorang, \& Mathews, 2011). The 
findings indicate that simulated presence therapy works better for some individuals than others (Miller et al., 2001; Peak \& Cheston, 2002). Challenges included recruitment and the support of a family member (O'Connor et al., 2011), agitation worsened in some individuals (Garland et al., 2007) and others rejected wearing headphones (Miller et al., 2001). Another consideration is the timing of introducing the intervention. One research team found that simulated presence was not effective when applied later in the agitation or when a person was hallucinating (Miller et al., 2001). Additionally, it was really important to have a strong bond with the person creating the audio to support the reduction of negative behaviours (Woods \& Ashley 1995). The findings indicated that matching the individual taking part in the intervention and their caregiver is essential to the success of the intervention. More robust research is needed in order to underpin the use of this intervention within a long-term care setting.

\section{Orientation and Activities of daily living}

The five studies included relating to orientation and activities of daily living were focused on the usability of various systems to support orientation, taking medication, washing hands and planning activities (Table 8). Two studies examined the usability of an automated handwashing system in long-term care facilities (Labelle \& Mihailidis, 2006; Mihailidis, Boger, Craig, \& Hoey, 2008). The prototype system was found to increase the person's ability to wash their hands without the help of a caregiver. The EMMA ${ }^{\circledR}$ medication dispensing device was explored by Ligon and colleagues (Ligons, Mello-Thoms, Handler, Romagnoli, \& Hochheiser, 2014). The findings indicated that the system was not user-friendly for people living with dementia and no individual successfully completed all the tasks. Digital planning boards were 
evaluated within a small-scale group accommodation (Kerkhof, Rabiee, \& Willems, 2011). The touchscreen enabled devices were displayed in both public and private spaces and could be personalised to illustrate a persons individual schedule. The findings indicated that more work needs to be undertaken in terms of functionality, ease of use, and installation reliability. However, the majority of participants felt the boards were useful and supported their memory. A case study outlined the use of an orientation system to support the individual with a message on a computer screen to inform them of the time of day, a prompt on what to do (i.e. stay in bed), and can illustrate any planned activities for the day (Baruch, Downs, Baldwin, \& Bruce, 2010). The system was found to decrease anxiety which led to a reduction in the late night calls made by the participant to family and friends when distressed and confused about the time of day.

Table 8. Characteristics of Orientation and Activities of Daily Living Intervention Studies

\section{Discussion}

The purpose of this systematic review was to identify the research undertaken on technology solutions within long-term care settings and to explore the extent to which people living with dementia were included in this research. An overview of the current literature has been presented which builds on the findings of previous reviews within this field (Fleming \& Sum, 2014; Gibson et al., 2014; Niemeijer et al., 2010; Topo, 2009). The original aspect of the present review is that it focuses solely on empirical studies exploring technology to support individuals with dementia living in a supported or residential care environments. The findings 
indicated a wide variety of systems and devices with large methodological heterogeneity. While this makes it challenging to draw any overarching conclusions about the technology used within care environments, we were able to categorise the literature in terms of six types of technology solutions: telecare, light therapy, robotic companion, well-being and leisure, simulated presence and to support orientation and activities of daily living.

In recent years, non-pharmacological interventions have gained recognition in the care of people living with dementia, however, robust evidence is still required to support their effectiveness (Cabrera et al., 2015). Technological interventions have indicated their potential to support person-centred care (Sugihara et al., 2013). Within this review, a wide range of positive outcomes were found through the use of technology solutions, including complementing staff care (Chan, Campo, Laval, \& Estève, 2002), providing tenants and residents with a sense of security (Margot-Cattin \& Nygård, 2006), enabling social interaction (Pfadenhauer \& Dukat, 2015; Šabanovic et al., 2009), enhancing well-being (Torrington, 2009) and promoting independence (Mihailidis et al., 2008). Also, the potential of robotic companions within long-term care settings was indicated, with further research currently underway (Moyle et al., 2015). Future research is recommended to compound the findings that have emerged from the review.

The review also indicated some challenges associated with the use of technology-based interventions, such as false alarms (Capezuti et al., 2009), reliability (Niemeijer et al., 2014), alarm fatigue (Niemeijer et al., 2014), no reduction in falls (Holmes et al., 2007), staff fear and reluctance to use technology (Niemeijer et al., 2014), and cost (Altus et al., 2000). Acceptance 
of the intervention by the person living with dementia can also be challenging (Moyle et al., 2016). Additionally, interventions need to be well defined and structured to be effective and useful. Light therapy, for example, could not be recommended in practice as there are a number of questions yet to be answered by further research (Forbes et al., 2014). In line with previous research, the issue of privacy emerged from the literature. Technology solutions were considered both an invasion of privacy (Niemeijer et al., 2015) and a way to prevent unneccesary intrusion on privacy (Yayama et al., 2013). Interestingly, the importance of keeping the data secure to uphold the privacy of the tenant or resident received little attention in the literature. It is also important to note that not all the interventions were successful in a population living with dementia (Ligons, Mello-Thoms, Handler, Romagnoli, \& Hochheiser, 2014) or with all the users (Peak \& Cheston, 2002). One study outlined the postive outcome for care when technology was removed from the care setting and replaced by reeducating staff (Bressler et al., 2011). This calls into question the quality of care when a technology intervention is implemented. These findings outline the need for a sensitive approach and a carefully considered intervention in advance of undertaking research in this setting.

The challenge with technology interventions is suggested by the variety of devices and systems to choose from. A combination of commercially available devices and research prototypes were reported. Studies exploring telecare devices had the largest number of papers included, within which a significant variation of systems were reported. A range of robotic companions were also found within the literature. The challenge with bright light therapy is that the best type of intervention has not yet been defined (Forbes et al., 2014). Equally, different factors impact on the simulated presence intervention, including the quality 
of audio recorded, the timing of the intervention and how it was delivered (i.e. iPad, headphones etc.) (O'Connor et al., 2011). A range of different factors can impact on the technology intervention before considering the variety of care environments people with dementia are living within. So, the challenge remains for long-term care environments to select the appropriate intervention when there is such a range of devices and variables that can impact on their success.

It is also important to consider if the severity of dementia has an impact on the technology intervention selected. One study implied that physical restraint was more commonly used with individuals in more advanced stages of dementia than telecare (Te Boekhorst et al., 2013). Solutions must be individual and enable customised features in order to complement person-centred care (Aloulou et al., 2013; Kerssens et al., 2014; Niemeijer et al., 2015). Consent to the use of technology in care is an important factor to ensure dignity, protective privacy, enhance security of information and promote person-centred care. Long-term care facilities should have protocols in place to adequately inform and obtain consent for the use of such interventions from the resident or tenant. This is particularly important if an individual moves into accommodation with built-in technologies installed that will be automatically used. A person-centred assessment of each individual's unique technology requirement is also recommended on an ongoing basis, as need is likely to change over time. Families and informal carers should be engaged in this process. A person may not need high levels of care when they first move into a care environment but this time can be used to obtain consent for any future care needs, including the use of technology. 
In line with previous findings, a major outcome is that more robust research is needed. It became clear that the methodological approaches ranged significantly across all the types of technology interventions and several different outcome measures were adopted. It is significant the small samples across all methodological approaches, with four studies having a sample size of one participant (Baruch et al., 2010; Bourennane et al., 2013; Chan et al., 2002; O'Connor et al., 2011). It is possible the small sample size was influenced by the number of people the technology intervention is available to or perhaps it was due to the perceived challenges associated with recruiting people living with dementia. A total of $N=31$ studies reported quantitative approaches, while $\mathrm{N}=17$ reported qualitative methods. The most commonly used methods of data collection were observation and validated measures e.g. The Quality of Life in Late-Stage Dementia (QUALID) Scale (Weiner et al., 2000). Observation was a frequently adopted method of including people living with dementia in the research design. Often the technology intervention was used on people living with dementia but their opinions on the outcome were not gathered. Where people living with dementia are reported as participants, it is not clear the authenticity of their involvement and often people living with dementia were largely passive participants within the research. One study stated that paid staff most familiar with residents completed questionnaires on their behalf (Te Boekhorst et al., 2013). It is therefore hard to establish the true engagement of people living with dementia in the research. Limited studies outlined the strong engagement and subsequent voice of people living with dementia within their studies (Godwin, 2012; Martin et al., 2013). Obtaining consent was often indicated within the papers but a significant lack of detail was evident when a combined approach of informed consent and proxy consent was adopted. When, who and how was the decision made regarding the individual with dementia's ability to give informed or proxy consent? Was the individual with dementia asked 
for assent? Would process consent enhance the person ability to engage in the research (Dewing, 2008)? It is recommended that future research outlines how individuals living with dementia are included, how they consent, how decisions are made between two approaches to consent when a combination of approaches are used and how they are supported to complete any validated measures both before and after the technology intervention.

\section{Limitations}

The search terms set out in the present systematic search were very specific. Perhaps wider search terms would have allowed a wider breath of included studies in the initial search. The three previous literature reviews increased the hand searched papers included in the study (Fleming \& Sum, 2014; Gibson et al., 2014; Topo, 2009). The search terms did not specifically focus on bright light therapy, simulated presence therapy or robotics, however, papers were retrieved within the original search and subsequent hand searches. The quality of the studies retrieved was not determined as the purpose was to obtain an overview of the type of research, the range of interventions and the involvement of people living with dementia in the studies. It is also possible that the screening and review processes may have been subject to interpretive bias. Additionally, the exclusion of conference papers may have omitted some relevant studies (for example Wada, Shibata, \& Kawaguchi, 2009).

Conclusions 
This systematic review presents sixty-one papers exploring the use of electronic assistive technology in long term care settings. The findings indicated the varied methodological approaches used to explore the impact of technology interventions. There was a significant lack of compelling evidence to indicate the technology intervention that is most effective. There are a wide range of devices and systems commercially available to support people living with dementia yet very little validated information to help caregivers select the most suitable technologies. Furthermore efforts to engage people living with dementia in the decision making should be expanded. Overall, the potential for technology solution to be incorporated within person-centred care provision is evident but more robust research is needed to compound these findings with people living with dementia as active participants.

\section{Acknowledgements}

XXXX

Aarts, M. P. J., Aries, M. B. C., Diakoumis, A., \& van Hoof, J. (2016). Shedding a Light on Phototherapy Studies with People having Dementia: A Critical Review of the Methodology from a Light Perspective. American Journal of Alzheimer's Disease and Other Dementias, 6, 1533317515628046-. http://doi.org/10.1177/1533317515628046

Aarts, M. P. J., Aries, M. B. C., Straathof, J., \& Hoof, J. v. (2014). Dynamic lighting systems in psychogeriatric care facilities in the Netherlands: a quantitative and qualitative analysis of stakeholders' responses and applied technology. Indoor and Built Environment, 24(5), 1420326X14532387-. http://doi.org/10.1177/1420326X14532387

Abbate, S., Avvenuti, M., \& Light, J. (2014). Usability Study of a wireless monitoring system among Alzheimer's disease elderly population. International Journal of Telemedicine and Applications, 2014. http://doi.org/10.1155/2014/617495

Aloulou, H., Mokhtari, M., Tiberghien, T., Biswas, J., Phua, C., Kenneth Lin, J. H., ... Yap, P. (2013). Deployment of assistive living technology in a nursing home environment: methods and lessons learned. BMC Medical Informatics and Decision Making, 13(1), 42. http://doi.org/10.1186/1472-6947-13-42

Altus, D. E., Mathews, R. M., Xaverius, P. K., Engelman, K. K., \& Nolan, B. a. D. (2000). Evaluating an electronic monitoring system for people who wander. American Journal of Alzheimer's Disease and Other Dementias, 15(2), 121-125. http://doi.org/10.1177/153331750001500201

Alzheimer's Disease International. (2015). World Alzheimer Report 2015. London, UK. 
Alzheimer's Disease International, 87. Retrieved from

https://www.alz.co.uk/research/WorldAlzheimerReport2015.pdf

Ancoli-Isreal, S., Gehrman, P., Martin, J. L., Shochat, T., Marler, M., Corey-Boom, J., \& Levi, L. (2003). Increased light exposure consolidates sleep and strengthens circadian rhythms in severe alzheimers disease patients. Behavioral Sleep Medicine, 1(1), 37-53.

http://doi.org/10.1207/S15402010BSM0101

Baruch, J., Downs, M., Baldwin, C., \& Bruce, E. (2010). A case study in the use of technology to reassure and support a person with dementia. Dementia, 9, 548-548.

http://doi.org/10.1177/1471301210384313

Bemelmans, R., Gelderblom, G. J., Jonker, P., \& de Witte, L. (2015). Effectiveness of Robot Paro in Intramural Psychogeriatric Care: A Multicenter Quasi-Experimental Study. Journal of the American Medical Directors Association, 16(11), 946-950. http://doi.org/10.1016/j.jamda.2015.05.007

Bemelmans, R., Gelderblom, G. J., Jonker, P., \& de Witte, L. (2016). How to use robot interventions in intramural psychogeriatric care; A feasibility study. Applied Nursing Research, 30, 154-157. http://doi.org/10.1016/j.apnr.2015.07.003

Bourennane, W., Charlon, Y., Bettahar, F., Campo, E., \& Esteve, D. (2013). Homecare monitoring system: A technical proposal for the safety of the elderly experimented in an alzheimer's care unit. Irbm, 34(2), 92-100.

http://doi.org/10.1016/j.irbm.2013.02.002

Braun, S. M., Kleynen, M., Bleijlevens, M. H. C., Moser, A., Beurskens, A. J., \& Lexis, M. a. (2014). "Interactive surfaces" technology as a potential tool to stimulate physical activity in psychogeriatric nursing home residents. Disability and Rehabilitation. Assistive Technology, 3107(November), 1-7. http://doi.org/10.3109/17483107.2014.904449

Bressler, K., E Redfern, R., \& Brown, M. (2011). Elimination of position-change alarms in an Alzheimer's and dementia long-term care facility. American Journal of Alzheimer's Disease and Other Dementias, 26(8), 599-605. http://doi.org/10.1177/1533317511432730

Broekens, J., Heerink, M., \& Rosendal, H. (2009). Assistive social robots in elderly care: a review. Gerontechnology, 8(2), 94-103. http://doi.org/10.4017/gt.2009.08.02.002.00.

Buckley, J. (2006). The importance of telecare for people with dementia. Nursing and Residential Care, 8(5), 212-215.

Burdea, G., Polistico, K., Krishnamoorthy, A., House, G., Rethage, D., Hundal, J., ... Pollack, S. (2014). Feasibility study of the BrightBrainer ${ }^{T M}$ integrative cognitive rehabilitation system for elderly with dementia. Disability and Rehabilitation. Assistive Technology, 10(5), 1-12. http://doi.org/10.3109/17483107.2014.900575

Cabrera, E., Sutcliffe, C., Verbeek, H., Saks, K., Meyer, G., Karlsson, S., \& On, A. Z. (2015). Non-pharmacological interventions as a best practice strategy in people with dementia living in nursing homes. A systematic review. European Geriatric Medicine, 6, 134-150. http://doi.org/10.1016/j.eurger.2014.06.003

Cahill, S., Begley, E., Faulkner, J. P., \& Hagen, I. (2007). Findings from Ireland on the use and usefulness of assistive technology for people with dementia. Technology and Disability, 19(Volume 19, Number 2-3 / 2007), 133-142.

Camberg, L., Woods, P., Ooi, W. L., \& Hurley, A. (1999). Evaluation of Simulated Presence : A Personalized Approach to Enhance Well-Being in Persons with Alzheimer' s Disease.

Capezuti, E., Brush, B. L., Lane, S., Rabinowitz, H. U., \& Secic, M. (2009). Bed-exit alarm 
effectiveness. Archives of Gerontology and Geriatrics, 49(1), 27-31.

http://doi.org/10.1016/j.archger.2008.04.007

Chan, M., Campo, E., Laval, E., \& Estève, D. (2002). Validation of a remote monitoring system for the elderly: Application to mobility measurements. Technology and Health Care, 10(5), 391-399.

Cheston, R., Thorne, K., Whitby, P., \& Peak, J. (2007). Simulated presence therapy, attachment and separation amongst people with dementia. Dementia, 6(3), 442-449. http://doi.org/10.1177/14713012070060030703

Cohen-Mansfield, J., \& Werner, P. (1997). Management of verbally disruptive behaviors in nursing home residents. Journal of Gerontology: Medical Sciences, 52A(6), M369M377. http://doi.org/10.1093/gerona/52A.6.M369

Dewing, J. (2008). Process Consent and Research with Older Persons Living with Dementia. Research Ethics, 4(2), 59-64. http://doi.org/10.1177/174701610800400205

Engstrom, M., Ljunggren, B., Lindqvist, R., \& Carlsson, M. (2005). Staff perceptions of job satisfaction and life situation before and 6 and 12 months after increased information technology support in dementia care.

Engström M, Lindqvist R, Ljunggren B, \& C. M. (2006). Relatives' opinions of IT support, perceptions of irritations and life satisfaction in dementia care. Journal of Telemedicine and Telecare, 12(5), 246-250. http://doi.org/10.1258/135763306777889127

Evans, N., Cheston, R., \& Harris, N. (2015). Personal message cards: An evaluation of an alternative method of delivering simulated presence therapy. Dementia (London, England), 1-13. http://doi.org/10.1177/1471301215574363

Fleming, R., \& Sum, S. (2014). Empirical studies on the effectiveness of assistive technology in the care of people with dementia: a systematic review. Journal of Assistive Technologies, 8(1), 14-34. http://doi.org/10.1108/JAT-09-2012-0021

Forbes, D., Culum, I., Lischka, A. R., Morgan, D. G., Peacock, S., Forbes, J., \& Forbes, S. (2014). Light therapy for managing cognitive, sleep, functional, behavioural, or psychiatric disturbances in dementia. Cochrane Database of Systematic Reviews, (4). http://doi.org/10.1002/14651858.CD003946.pub3

Garland, K., Beer, E., Eppingstall, B., \& O'Connor, D. (2007). A Comparison of Two Treatments of Agitated Behavior in Nursing Home ... The American Journal of Geriatric Psychiatry, 15(6), 514-521.

Gibson, G., Newton, L., Pritchard, G., Finch, T., Brittain, K., \& Robinson, L. (2014). The provision of assistive technology products and services for people with dementia in the United Kingdom. Dementia, (May), 1-21. http://doi.org/10.1177/1471301214532643

Godwin, B. (2012). The ethical evaluation of assistive technology for practitioners: a checklist arising from a participatory study with people with dementia, family and professionals. Journal of Assistive Technologies, 6(2), 123-135. http://doi.org/10.1108/17549451211234975

Higgins, P. (2013). Involving people with dementia in research. Nursing Times, 109(28), 2023.

Holmes, D., Teresi, J. a, Ramirez, M., Ellis, J., Eimicke, J., Jian Kong, ... Silver, S. (2007). An evaluation of a monitoring system intervention: falls, injuries, and affect in nursing homes. Clinical Nursing Research, 16(4), 317-335.

http://doi.org/10.1177/1054773807307870

Jøranson, N., Pedersen, I., Rokstad, A. M. M., \& Ihlebæk, C. (2015). Effects on Symptoms of Agitation and Depression in Persons With Dementia Participating in Robot-Assisted 
Activity: A Cluster-Randomized Controlled Trial. Journal of the American Medical Directors Association, 16(10), 867-873. http://doi.org/10.1016/j.jamda.2015.05.002

Kachouie, R., Sedighadeli, S., Khosla, R., \& Chu, M.-T. (2014). Socially Assistive Robots in Elderly Care: A Mixed-Method Systematic Literature Review. International Journal of Human-Computer Interaction, 30(5), 369-393.

http://doi.org/10.1080/10447318.2013.873278

Kerkhof, Y., Rabiee, F., \& Willems, C. G. (2011). Memory aid to structure and support daily activities for people with dementia. Assistive Technology Research Series, 29, 3-9. http://doi.org/10.3233/978-1-60750-814-4-3

Kerssens, C., Sattler, M., \& Monteiro, A. (2014). Managing dementia symptoms and needs using technology. Journal of Gerontological Nursing, 40(7), 16-20. http://doi.org/10.3928/00989134-20140513-01

Labelle, K. L., \& Mihailidis, A. (2006). The use of automated prompting to facilitate handwashing in persons with dementia. American Journal of Occupational Therapy, 60(4), 442-450.

Leroi, I., Woolham, J., Gathercole, R., Howard, R., Dunk, B., Fox, C., ... Ritchie, C. (2013). Does telecare prolong community living in dementia? A study protocol for a pragmatic, randomised controlled trial. Trials, 14(1), 349. http://doi.org/10.1186/1745-6215-14349

Libin, A., \& Cohen-Mansfield, J. (2004). Therapeutic robocat for nursing home residents with dementia: preliminary inquiry. American Journal of Alzheimer's Disease and Other Dementias, 19(2), 111-116. http://doi.org/10.1177/153331750401900209

Ligons, F. M., Mello-Thoms, C., Handler, S. M., Romagnoli, K. M., \& Hochheiser, H. (2014). Assessing the impact of cognitive impairment on the usability of an electronic medication delivery unit in an assisted living population. International Journal of Medical Informatics, 83(11), 841-848. http://doi.org/10.1016/j.ijmedinf.2014.07.004

Lyketsos, C. G., Carrillo, M. C., Ryan, J. M., Khachaturian, A. S., Trzepacz, P., Amatniek, J., ... Miller, D. S. (2012). Neuropsychiatric symptoms in Alzheimer's disease. Alzheimers Dement, 7(5), 532-539. http://doi.org/10.1016/j.jalz.2011.05.2410.Neuropsychiatric

Margot-Cattin, I., \& Nygård, L. (2006). Access technology and dementia care: Influences on residents' everyday lives in a secure unit. Scandinavian Journal of Occupational Therapy, 13(2), 113-124. http://doi.org/10.1080/11038120600673056

Martin, S., Augusto, J. C., Mccullagh, P., Carswell, W., Zheng, H., Wang, H., ... Mulvenna, M. (2013). Participatory research to design a novel telehealth system to support the nighttime needs of people with dementia: NOCTURNAL. International Journal of Environmental Research and Public Health, 10(12), 6764-6782. http://doi.org/10.3390/ijerph10126764

Martínez-Alcalá, C. I., Pliego-Pastrana, P., Rosales-Lagarde, A., Lopez-Noguerola, J., \& Molina-Trinidad, E. M. (2016). Information and Communication Technologies in the Care of the Elderly: Systematic Review of Applications Aimed at Patients With Dementia and Caregivers. JMIR Rehabilitation and Assistive Technologies, 3(1), e6. http://doi.org/10.2196/rehab.5226

Mihailidis, A., Boger, J. N., Craig, T., \& Hoey, J. (2008). The COACH prompting system to assist older adults with dementia through handwashing: an efficacy study. $B M C$ Geriatrics, 8(1), 28. http://doi.org/10.1186/1471-2318-8-28

Miller, S., Vermeersch, P. E. H., Bohan, K., Renbarger, K., Kruep, A., \& Sacre, S. (2001). Audio presence interventions for decreasing agitation in people with dementia. Geriatric 
Nursing, 22(2), 66-70. http://doi.org/10.1177/1471301211421074

Miskelly, F. (2004). A novel system of electronic tagging in patients with dementia and wandering. Age and Ageing, 33(3), 304-306. http://doi.org/10.1093/ageing/afh084

Moher, D., Liberati, A., Tetzlaff, J., Altman, D. G., \& Grp, P. (2009). Preferred Reporting Items for Systematic Reviews and Meta-Analyses: The PRISMA Statement (Reprinted from Annals of Internal Medicine). Physical Therapy, 89(9), 873-880.

http://doi.org/10.1371/journal.pmed.1000097

Mordoch, E., Osterreicher, A., Guse, L., Roger, K., \& Thompson, G. (2013). Use of social commitment robots in the care of elderly people with dementia: A literature review. Maturitas, 74(1), 14-20. http://doi.org/10.1016/j.maturitas.2012.10.015

Moyle, W., Beattie, E., Draper, B., Shum, D., Thalib, L., Jones, C., ... Mervin, C. (2015). Effect of an interactive therapeutic robotic animal on engagement, mood states, agitation and psychotropic drug use in people with dementia: a cluster-randomised controlled trial protocol. BMJ Open, 5(8), e009097. http://doi.org/10.1136/bmjopen-2015-009097

Moyle, W., Jones, C., Sung, B., Bramble, M., O'Dwyer, S., Blumenstein, M., \& Estivill-Castro, V. (2016). What Effect Does an Animal Robot Called CuDDler Have on the Engagement and Emotional Response of Older People with Dementia? A Pilot Feasibility Study. International Journal of Social Robotics, 8(1), 145-156. http://doi.org/10.1007/s12369015-0326-7

Niemeijer, A. R., Depla, M. F. I. A., Frederiks, B. J. M., \& Hertogh, C. M. P. M. (2015). The experiences of people with dementia and intellectual disabilities with surveillance technologies in residential care. Nursing Ethics, 22(3), 307-20.

http://doi.org/10.1177/0969733014533237

Niemeijer, A. R., Depla, M., Frederiks, B., Francke, A. L., \& Hertogh, C. (2014). The Use of Surveillance Technology in Residential Facilities for People with Dementia or Intellectual Disabilities: A Study Among Nurses and Support Staff. American Journal of Nursing, 114(12), 28-37. http://doi.org/10.1097/01.NAJ.0000457408.38222.d0

Niemeijer, A. R., Frederiks, B. J. M., Riphagen, I. I., Legemaate, J., Eefsting, J. a, \& Hertogh, C. M. P. M. (2010). Ethical and practical concerns of surveillance technologies in residential care for people with dementia or intellectual disabilities: an overview of the literature. International Psychogeriatrics / IPA, 22(7), 1129-1142.

http://doi.org/10.1017/S1041610210000037

Nijhof, N., van Gemert-Pijnen, J. E. W. C., de Jong, G. E. N., Ankoné, J. W., \& Seydel, E. R. (2012). How assistive technology can support dementia care: A study about the effects of the IST Vivago watch on patients' sleeping behavior and the care delivery process in a nursing home. Technology and Disability, 24(2), 103-115. http://doi.org/10.3233/TAD-2012-0339

Nijhof, N., van Hoof, J., van Rijn, H., \& van Gemert-Pijnen, J. E. W. C. (2013). The behavioral outcomes of a technology-supported leisure activity in people with dementia.

Technology \& Disability, 25(4), 263-273. http://doi.org/10.3233/TAD-140398

O'Connor, C. M., Smith, R., Nott, M. T., Lorang, C., \& Mathews, R. M. (2011). Using video simulated presence to reduce resistance to care and increase participation of adults with dementia. American Journal of Alzheimer's Disease and Other Dementias, 26(4), 317-25. http://doi.org/10.1177/1533317511410558

$\varnothing$ derud, T., Landmark, B., Eriksen, S., \& Berit, A. (2013). Exploring the use of GPS for Locating Persons with Dementia. Aaate.

Olsson, A., Engström, M., Skovdahl, K., \& Lampic, C. (2012). My, your and our needs for 
safety and security: Relatives' reflections on using information and communication technology in dementia care. Scandinavian Journal of Caring Sciences, 26(1), 104-112. http://doi.org/10.1111/j.1471-6712.2011.00916.x

Paavilainen, P., Korhonen, I., \& Partinen, M. (2005). Telemetric activity monitoring as an indicator of long term change $s$ in health and well -being of older people Telemetric activity monitoring. Gerontechnology, 4(2), 77-85.

Padala, K. P., Padala, P. R., Malloy, T. R., Geske, J. A., Dubbert, P. M., Dennis, R. A., ... Sullivan, D. H. (2012). Wii-fit for improving gait and balance in an assisted living facility: A pilot study. Journal of Aging Research, 2012. http://doi.org/10.1155/2012/597573

Peak, J., \& Cheston, R. (2002). Using simulated presence therapy with people with dementia. Aging \& Mental Health, 6(October 2000), 77-81. http://doi.org/10.1080/1360786012010109

Pfadenhauer, M., \& Dukat, C. (2015). Robot Caregiver or Robot-Supported Caregiving?: The Performative Deployment of the Social Robot PARO in Dementia Care. International Journal of Social Robotics, 7(3), 393-406. http://doi.org/10.1007/s12369-015-0284-0

Robinson, H., MacDonald, B. A., Kerse, N., \& Broadbent, E. (2013). Suitability of Healthcare Robots for a Dementia Unit and Suggested Improvements. Journal of the American Medical Directors Association, 14(1), 34-40. http://doi.org/10.1016/j.jamda.2012.09.006

Šabanovic, S., Bennett, C. C., Chang, W., \& Huber, L. (2009). PARO Robot Affects Diverse Interaction Modalities in Group Sensory Therapy for Older Adults with Dementia.

Schikhof, Y., Mulder, I., \& Choenni, S. (2010). Who will watch (over) me? Humane monitoring in dementia care. International Journal of Human Computer Studies, 68(6), 410-422. http://doi.org/10.1016/j.ijhcs.2010.02.002

Sugihara, T., Fujinami, T., Phaal, R., \& Ikawa, Y. (2013). A technology roadmap of assistive technologies for dementia care in Japan. Dementia, 1471301213493798-. http://doi.org/10.1177/1471301213493798

Tamura, T., Yonemitsu, S., Itoh, A., Oikawa, D., \& al, et. (2004). Is an Entertainment Robot Useful in the Care of Elderly People With Severe Dementia? The Journals of Gerontology, 59A(1), 83-85. Retrieved from http://myaccess.library.utoronto.ca/login?url=http://search.proquest.com/docview/20 8615585 ?accountid=14771\%5Cnhttp://bf4dv7zn3u.search.serialssolutions.com/?ctx_v er=Z39.88-2004\&ctx_enc=info:ofi/enc:UTF8\&rfr_id=info:sid/ProQ:healthcompletealumnishell\&rft

Te Boekhorst, S., Depla, M. F. I. A., Francke, A. L., Twisk, J. W. R., Zwijsen, S. A., \& Hertogh, C. M. P. M. (2013). Quality of life of nursing-home residents with dementia subject to surveillance technology versus physical restraints: An explorative study. International Journal of Geriatric Psychiatry, 28(4), 356-363. http://doi.org/10.1002/gps.3831

Thorpe, L., Middleton, J., Russell, G., \& Stewart, N. (2000). Bright light therapy for demented nursing home patients with behavioral disturbance, 15(1), 18-26.

Topo, P. (2009). Technology studies to meet the needs of people with dementia and their caregivers a literature review. Journal of Applied Gerontology (Vol. 28).

http://doi.org/10.1177/0733464808324019

Torrington, J. (2009). The design of technology and environments to support enjoyable activity for people with dementia. Alter, 3(2), 123-137.

http://doi.org/10.1016/j.alter.2009.01.005

van Wezel, C., Zwerts-Verhelst, E. L. M., Sturm, J., \& van Hoof, J. (2016). An explorative 
study of the beliefs of staff of psychogeriatric nursing homes regarding the use of dynamic lighting systems. Technology in Society.

http://doi.org/10.1016/j.techsoc.2016.09.001

Wada, K., Shibata, T., \& Kawaguchi, Y. (2009). Long-term robot therapy in a health service facility for the aged - A case study for 5 years -. In 2009 IEEE International Conference on Rehabilitation Robotics (pp. 930-933). IEEE. http://doi.org/10.1109/ICORR.2009.5209495

Weiner, M. F., Martin-Cook, K., Svetlik, D. A., Saine, K., Foster, B., \& Fontaine, C. S. (2000). The quality of life in late-stage dementia (QUALID) scale. Journal of the American Medical Directors Association, 1(3), 116-116.

Woods, P., \& Ashley, J. (1995). Simulated Presence Therapy : Using Selected Memories To Manage Problem Behaviors In A I z h e I m e r's D i s e a s e Patients. Geriatric Nursing, 16(1), 9-14.

Yamakawa, M., Suto, S., Shigenobu, K., Kunimoto, K., \& Makimoto, K. (2012). Comparing dementia patients' nighttime objective movement indicators with staff observations. Psychogeriatrics, 12(1), 18-26. http://doi.org/10.1111/j.1479-8301.2011.00380.x

Yayama, S., Yamakawa, M., Suto, S., Greiner, C., Shigenobu, K., \& Makimoto, K. (2013). Discrepancy between subjective and objective assessments of wandering behaviours in dementia as measured by the Algase Wandering Scale and the Integrated Circuit tag monitoring system. Psychogeriatrics, 13(2), 80-87. http://doi.org/10.1111/psyg.12011

Zwijsen, S. A., Depla, M. F. I. A., Niemeijer, A. R., Francke, A. L., \& Hertogh, C. M. P. M. (2012). Surveillance technology: An alternative to physical restraints? A qualitative study among professionals working in nursing homes for people with dementia. International Journal of Nursing Studies, 49(2), 212-219.

http://doi.org/10.1016/j.ijnurstu.2011.09.002

Zwijsen, S. A., Niemeijer, A. R., \& Hertogh, C. M. P. M. (2011). Ethics of using assistive technology in the care for community-dwelling elderly people: An overview of the literature. Aging \& Mental Health, 15(4), 419-427.

http://doi.org/10.1080/13607863.2010.543662 